\title{
Methodologies for identifying food system research priorities: Dispatch from Alaska
}

\author{
Elizabeth Hodges Snyder ${ }^{\mathrm{a}, *}$ and Shannon Donovan ${ }^{\mathrm{b}}$ \\ University of Alaska Anchorage
}

Submitted June 18, 2013 / Revised September 11, 2013 / Published online September 17, 2013

Citation: Snyder, E. H., \& Donovan, S. (2013). Methodologies for identifying food system research priorities:

Dispatch from Alaska. Journal of Agriculture, Food Systems, and Community Development, 3(4), 183-199.

http://dx.doi.org/10.5304/jafscd.2013.034.024

Copyright (C) 2013 by New Leaf Associates, Inc.

\begin{abstract}
Alaska faces unique challenges to sustainable food systems and food security, including extreme
\end{abstract}

a Elizabeth Hodges Snyder, PhD, MPH, Department of Health Sciences, College of Health, University of Alaska Anchorage (UAA), Anchorage, Alaska

Elizabeth Hodges Snyder is an assistant professor of public health and a soil scientist in the Department of Health Sciences at the University of Alaska Anchorage. She also serves as co-chair of the Alaska Food Policy Council Research and Information Working Group.

* Corresponding author: Elizabeth Hodges Snyder, Department of Health Sciences, 3211 Providence Drive, DPL 405, University of Alaska Anchorage, Anchorage, Alaska 99508 USA; +1-907-786-6541; ehodges4@uaa.alaska.edu

b Shannon Donovan, PhD, Department of Geography and Environmental Studies, College of Arts and Sciences, University of Alaska Anchorage, Anchorage, Alaska USA

Shannon Donovan is an assistant professor of environmental studies in the Department of Geography and Environmental Studies at the University of Alaska Anchorage. climate conditions and geographical remoteness, and yet the state is similar to the "Lower 48" states with respect to many indicators that can be used to characterize the health of our food systems. Due to common concerns over such indicators as obesity rates, food insecurity rates, and recruitment of new farmers, food system stakeholders in Alaska are promoting a resurgence of food systems research and advocacy that is exemplified in the work of the Alaska Food Policy Council (AFPC). Identifying and prioritizing the specific food systems research needs of a state as large and diverse as Alaska is a challenge, but one that is being met with methodical, straightforward approaches. This commentary outlines two examples of recent formal, yet relatively simple, methods for identifying food system research and action priorities, and concludes by sharing some of the latest identified Alaska food system priority research projects, ideas, and needs.

\section{Keywords}

Alaska, food security, food systems 


\section{Introduction}

Alaska is a culturally diverse state unified in the pride it takes in self-sufficiency, toughness, and a general "can-do" attitude when it comes to procuring sustenance from the land and sea. The forward-looking, rugged optimism encapsulated by our state motto, "North to the Future" (adopted by the Alaska Legislature in 1967 during the centennial celebration of the Alaska Purchase), is coarsely exemplified in such reality show hits as "Deadliest Catch," "Ultimate Survival," "Great Bear Stakeout," "Life Below Zero," and "Ice Road Truckers." Less flashy, food-related examples of self-reliance and ingenuity in the "frozen north" include food storage cellars dug into the permafrost; the delicate political and environmental balance maintained between commercial, subsistence, and recreational fishermen; the variety of traditional Alaska Native food procurement and preservation techniques passed down for generations; the use of geothermal energy to heat greenhouses even when outside temperatures dip well below zero degrees Fahrenheit; and the recent designation of Anchorage as a top ten-community with respect to the number of community gardens per capita (Center for City Park Excellence, The Trust for Public Land, 2013).

Yet, despite the unique challenges posed by geographical remoteness and extreme climate, or to look at it another way, despite innovative solutions to those challenges, Alaska is not unique from the "Lower 48" states with respect to a variety of indicators that can be used to characterize the health of our food systems. Approximately 15 percent of households in the U.S. are food insecure, and a similar percentage of households in Alaska (12 percent) also experience food insecurity (Nord, Andrews, \& Carlson, 2008). The prevalence of overweight (including obesity) in adults nationally is also similar to that in Alaska (69) percent and 65 percent, respectively) (Levi, Segal, St. Laurent, \& Kohn, 2011). And, shifting from the consumption to the production end of things, recruiting and retaining young farmers is a challenge at any U.S. latitude, as evidenced by the fact that the average age of farm operators both nationally and in Alaska is between 50 and 60 years (USDA, 2009).
Meanwhile, a figurative "food pipeline" is pumping in the opposite direction from the transAlaska oil pipeline. It's estimated that Alaska imports about 95 percent of its food (Helfferich \& Tarnai, 2010), while producing a mere US $\$ 30$ million in agricultural products annually (USDA, 2009). This trade imbalance, together with the indicators of the health of the food system noted previously, make up much of the justification for the latest resurgence in food systems research, promotion, and advocacy in Alaska. In this commentary we'd like to share two recent approaches to identifying food system research and action priorities. We conclude by sharing some of the latest Alaska food system priority research projects, ideas, and needs that have been identified.

\section{Approaches to Identifying Food System Research and Action Priorities}

The approaches to identifying food system research and action priorities were formal, yet relatively simple, and employed such methodologies as targeted crowd-sourcing, key informant interviews, a workshop, and literature review. The two data collection efforts illustrated in figure 1, below, technically were conducted independently, but involved overlapping groups of researchers and stakeholders. Their findings will be used collectively.

\section{Data Collection Templates}

The first example of an ongoing effort to identify food system research priorities is the development of "research inventory" and "action plan" templates (see the appendices) utilized and shared by various workgroups of the Alaska Food Policy Council (AFPC). The AFPC formed in early 2010 with the "intent to provide recommendations and information to agencies, businesses, organizations, and individual consumers, with well-developed comprehensive policies that improve Alaska's food systems" (Agnew::Beck Consulting, 2012, p. 5). With contributions from membership composed of federal and state agencies, tribal entities, university programs, farmers, fisheries, and food systems businesses, the AFPC published a strategic plan in January 2012. The plan defines the council's vision, core values, mission, goals, objectives, and 
strategies, with a special emphasis on those strategies identified as priorities for the following three years (2012-2015). One such priority strategy is to "develop AFPC's role as research aggregator and resource" (Agnew::Beck Consulting, 2012, p. 7), which falls under the objective to "improve the body of research that will inform and support Alaska food policy efforts" (Agnew::Beck Consulting, 2012, p. 7) and the goal to engage Alaskans in the food system. In June 2012, the AFPC released a general call recruiting members to join workgroups organized to implement specific components of the strategic plan, and one such group is the Research and Information Workgroup (RWG).

The members of the RWG, in working to develop a list of priority research needs and questions, realized they first needed to have a better handle on what research their own members (and other researchers in Alaska) were already conducting, had conducted, or planned to conduct. To this end, the RWG collaborated with an Alaska

Figure 1. Relative Timing and Process of Example Alaska Research Priority Identification Activities, 2012-2013

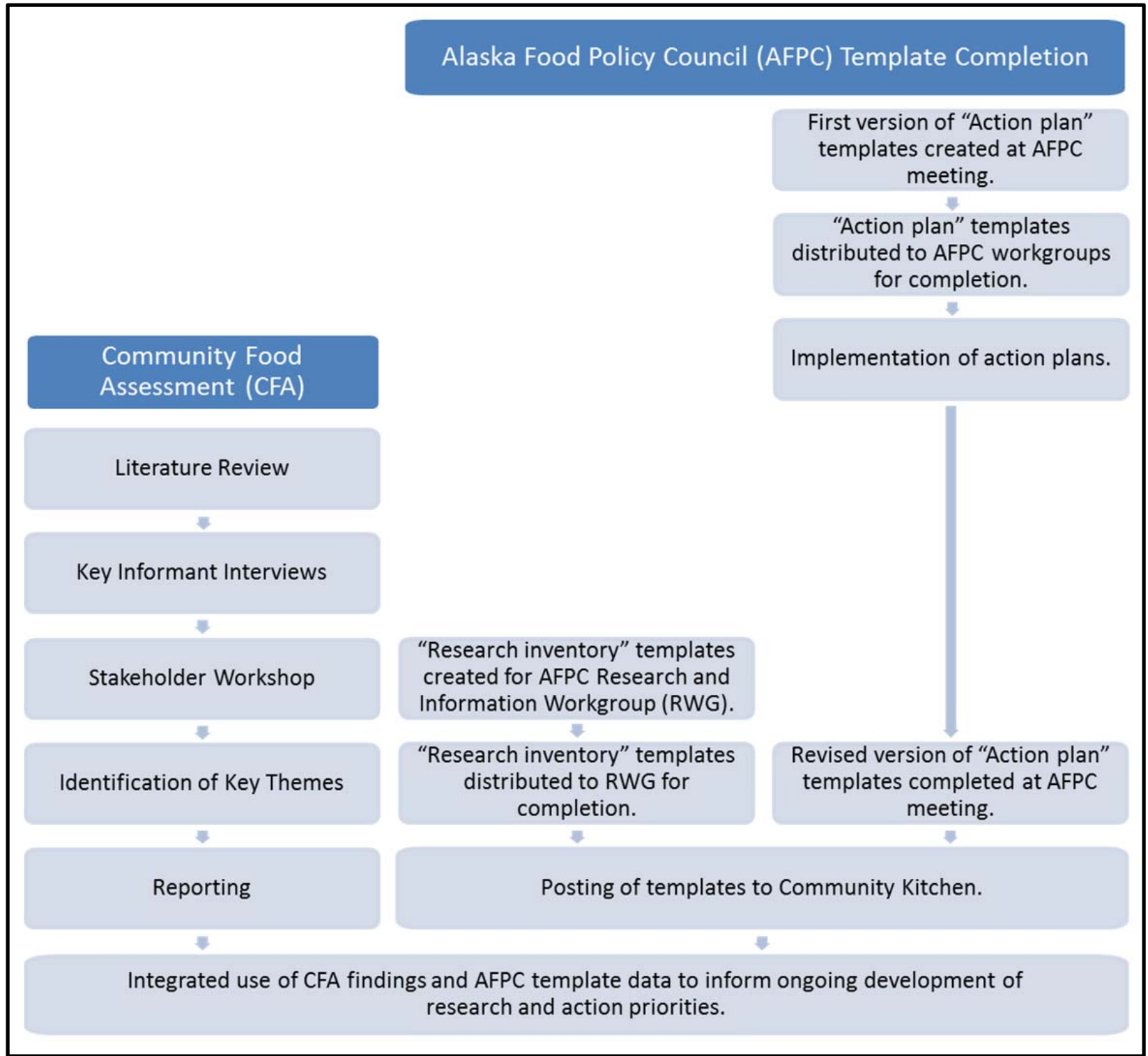


consulting firm to develop a "research inventory" (sometimes called a "project and research idea") template, which is currently being filled in by workgroup members via email communications and conference calls. The template is designed to capture key information on past, current, and future research, including project titles, keywords, participating organizations, participating researchers, dates of template revision, and other supplemental notes. The method of formally documenting workgroup ideas and identified needs is also employed by AFPC "action plan" templates used by all of the AFPC workgroups, by which they can report current and proposed actions and projects designed to meet AFPC goals and objectives. Action plans were most recently updated during a May 2013 AFPC meeting. The various templates are posted to the AFPC "Community Kitchen," a Google site created for internal communication and document storage. Workgroups can view one another's templates to round out their own action plans, find synergy between workgroups, and "cross-pollinate." For example, other workgroups can review research projects posted by the RWG and propose additional activities that would fill strategy data gaps not otherwise addressed. Conversely, RWG members can view other workgroup action plan templates to prioritize research projects that would support specific action plan activities. In fall 2013, the RWG plans to review the templates and prioritize research efforts based on such criteria as the AFPC goals and objectives, available expertise, and funding opportunities. At the end of this commentary, we present some preliminary research priorities identified through the templates along with findings from our second example research priority identification approach: a modified community food assessment (CFA) conducted by researchers at the University of Alaska Anchorage (UAA) at the behest of a private Alaska-based foundation.

\section{Community Food Assessment (CFA)}

In 2013, in our role as UAA faculty members we completed a targeted CFA to assist a local foundation in characterizing the status, challenges, and opportunities with respect to Alaska food security and local food production. We wished to understand better the current status of food production in Alaska and to identify options that could stimulate the expansion of local food production and promote overall food security within our state. We utilized a combination of approximately 50 key informant interviews, an interactive workshop, and a review of the literature to collect data that ultimately fell into four key themes of need: production; processing and packaging; distributing, retailing, and demand; and information and communication. Common to all of these themes was the need for additional research to better inform the design, implementation, and evaluation of proposed projects. We compiled the findings of the CFA in a white paper for public use, while detailed methodologies, results, and discussion will be submitted for publication in the peer-reviewed literature (manuscript under preparation). The RWG will add the CFA findings to the figurative decision-making toolbox for identifying and prioritizing specific research efforts.

\section{Preliminary Findings}

Some of the preliminary research needs, ideas, and projects for the Alaska food system identified through the AFPC templates and the CFA are general in nature and are common to food systems outside our state, including development of a concept map with existing data and research on the food system; a detailed gap analysis of the food system and its components; an assessment of the benefits of local foods to the economy; and development of a white paper that outlines a comprehensive food system research approach. Other potential research priorities are much more specific and pertain to the geographic, climatic, sociodemographic, and economic realities of Alaska. With respect to the "production" theme, our findings suggest a need to prioritize research that helps us answer questions regarding how to increase volume and consistency of local products (for example, what varieties are most successful in a short, cool growing season? How do we grow best indoors?), support protection and provision of land (much arable, remote land in Alaska is underdeveloped, while other areas are under threat 
of urban development), improve access to equipment (shipping is often cost-prohibitive), increase the number of farmers (how do we get people started and motivated to stay in a challenging environment?), and expand farming across the state.

The "processing and packaging" theme primarily relates to the relative lack of agricultural infrastructure in Alaska. Our state has a great need for processing plants to produce value-added foods (even as simple as washed and cut greens), and for short- and long-term storage facilities - both for export and for emergency supplies. On an individual level, Alaskans long ago mastered and embraced smoking, fermenting, canning, and storing local foods, but large-scale commercial facilities are lacking.

Next in the food system matrix comes the "distributing, retailing, and demand" theme. How do we best promote coordinated, cooperative mechanisms to meet demands of large retailers and their customers, in light of the fact that locally produced foods are currently more expensive, produced in smaller quantities, and available during shorter growing seasons than products sourced outside Alaska? Or better yet, from a production perspective, how do we reduce these limitations? With respect to the "demand" theme, it is clear that public marketing, campaigning, outreach, and education to address the connection between local food, cultural traditions, health, and nutrition is in order. In fact, the need to increase demand for local (and healthy) foods is already well recognized, as evidenced by programs such as the active Alaska Department of Natural Resources (DNR) Farm to School Program, new fish-to-school programs being piloted and evaluated around the state, and the acceptance of food stamps at Alaska farmers' markets.

The fourth and final theme identified in the CFA and reflected in the AFPC templates is "information and communication." Specifically, key stakeholders request additional supports for farmer education and a centralized clearinghouse of information related to Alaska local food production and food security. Questions surrounding these needs include how best to develop, deliver, and maintain services and resources. The AFPC will likely have a central role.

\section{In Closing}

Research, of course, isn't the sole solution to the food system needs in Alaska, but instead plays a supporting role. Research (and evaluation) designed and conducted with the intent to be applied to the discussed themes through such avenues as developing business plans, agricultural methods, funding initiatives, communication strategies, events and outreach materials, collaborative efforts, food policy, human resources, and new programs will be of greatest use. Such research, whether formal or informal, is and will be conducted by the same range of stakeholders involved in the AFPC, including academics in the natural and social sciences, economics, and policy fields (for example), state and federal agencies, nongovernmental organizations (NGOs), community organizations, Tribal entities, funders, businesses, and producers. As members of academia, we look forward to continuing to collaborate with these community partners in strengthening the Alaska food systems on which we all rely.

\section{Acknowledgements}

Thank you to members of the Alaska Food Policy Council board and the Agnew::Beck consulting firm for their assistance in reviewing and confirming the information in this commentary. We would also like to credit Amy Petit with the Alaska Department of Natural Resources with sharing the term "food pipeline" to describe food imports to Alaska.

\section{References}

Agnew::Beck Consulting. (2012). Alaska Food Policy Council (AFPC) strategic plan 2012-2015. Retrieved from http://sitkalocalfoodsnetwork.files. wordpress.com/2012/03/afpc-2012-strategicplan_final.pdf

Center for City Park Excellence, The Trust for Public Land. (2013). Park agency community garden plots per 10,000 residents [Unpublished data set]. Washington, D.C.: Author. 
Helfferich, D., \& Tarnai, N. (2010). Alaska’s food (in)security. Agroborealis, 41(1), 23-27. http://www.uaf.edu/snras/publications/

Levi, J., Segal, L. M., St. Laurent, R., \& Kohn, D. (2011). $F$ as in fat: How obesity threatens America's future. Washington, D.C.: Trust for America's Health. Retrieved from http://healthyamericans.org/ assets/files/TFAH2011FasInFat10.pdf
Nord, M., Andrews, M., \& Carlson, S. (2008). Household food security in the United States, 2008 (Economic Research Report No. ERR-83). Washington, D.C.: U.S. Department of Agriculture. Retrieved from http://www.ers.usda.gov/Publications/ERR83/ ERR83.pdf

U.S. Department of Agriculture. (2009). 2007 Census of agriculture. Volume 1, U.S. summary and state reports. Retrieved from http://www.agcensus.usda.gov/ Publications/2007/Full Report/ 


\section{Goal 1: All Alaskans have access to affordable, healthy (preferably local) foods.}

Priority strategies: Develop, strengthen, and expand the school-based programs and policies that educate about and provide healthy, local foods to schools (e.g., Farm to School Program, Agriculture in the Classroom, traditional foods in schools, school gardens).

Strengthen enforcement language in the Local Agricultural and Fisheries Products Preference Statute (AS 36.15.050), also known as the "Seven Percent" statute, and Procurement Preference for State Agricultural and Fisheries Products (Sec. 29.71.040).

\begin{tabular}{|l|l|l|l|l|}
\hline \multicolumn{2}{|l|}{ Current Research Projects } & Organization(s) & Researcher(s) & Other Notes \\
\hline Project Title & Keywords & & & \\
\hline & & & & \\
\hline & & & & \\
\hline & & & & \\
\hline & & & & \\
\hline & & & & \\
\hline & & & & \\
\hline & & & & \\
\hline
\end{tabular}


Goal 1: All Alaskans have access to affordable, healthy (preferably local) foods.

\section{Ideas for Future Research}

\begin{tabular}{|l|l|l|l|l|}
\hline Topic & Keywords & Possible Partners? & Your Name & Other Notes \\
\hline & & & & \\
\hline & & & & \\
\hline & & & & \\
\hline & & & & \\
\hline & & & & \\
\hline & & & & \\
\hline
\end{tabular}




\begin{tabular}{|l|l|l|l|l|}
\hline Current Research Projects & Organization(s) & Researcher(s) & Other Notes \\
\hline Project Title & Keywords & & & \\
\hline & & & & \\
\hline & & & & \\
\hline & & & & \\
\hline & & & & \\
\hline & & & & \\
\hline & & & & \\
\hline & & & & \\
\hline & & & & \\
\hline
\end{tabular}




\begin{tabular}{|l|l|l|l|l|}
\hline Ideas for Future Research & Possible Partners? & Your Name & Other Notes \\
\hline Topic & Keywords & & & \\
\hline & & & & \\
\hline & & & & \\
\hline & & & & \\
\hline & & & & \\
\hline & & & & \\
\hline
\end{tabular}




\begin{tabular}{|l|l|l|l|l|}
\hline Current Research Projects & Organization(s) & Researcher(s) & Other Notes \\
\hline Project Title & Keywords & & & \\
\hline & & & & \\
\hline & & & & \\
\hline & & & & \\
\hline & & & & \\
\hline & & & & \\
\hline & & & & \\
\hline
\end{tabular}


Goal 3: Food is safe, protected and supplies are secure throughout Alaska.

\section{Ideas for Future Research}

Keywords

Possible Partners?

\begin{tabular}{|l|l|l|}
\hline Your Name & Other Notes \\
\hline & & \\
\hline & & \\
\hline & & \\
\hline & & \\
\hline
\end{tabular}


Current Research Projects

\begin{tabular}{|c|c|c|c|c|}
\hline Project Title & Keywords & Organization(s) & Researcher(s) & Other Notes \\
\hline & & & & \\
\hline & & & & \\
\hline & & & & \\
\hline & & & & \\
\hline & & & & \\
\hline & & & & \\
\hline & & & & \\
\hline & & & & \\
\hline & & & & \\
\hline & & & & \\
\hline & & & & \\
\hline
\end{tabular}


Goal 4: Alaska's food system is more sustainable.

Priority strategy None currently

\section{Ideas for Future Research}

\begin{tabular}{|c|c|c|c|c|}
\hline Topic & Keywords & Possible Partners? & Your Name & Other Notes \\
\hline & & & & \\
\hline & & & & \\
\hline & & & & \\
\hline & & & & \\
\hline & & & & \\
\hline & & & & \\
\hline & & & & \\
\hline & & & & \\
\hline
\end{tabular}


Priority strategies Develop AFPC's role as research aggregator and resource.

Identify and support existing local food system leaders, projects, events and activities that support Alaska's food system.

\begin{tabular}{|c|c|c|c|c|}
\hline Project Title & Keywords & Organization(s) & Researcher(s) & Other Notes \\
\hline & & & & \\
\hline & & & & \\
\hline & & & & \\
\hline & & & & \\
\hline & & & & \\
\hline & & & & \\
\hline & & & & \\
\hline & & & & \\
\hline & & & & \\
\hline & & & & \\
\hline & & & & \\
\hline
\end{tabular}


Develop AFPC's role as research aggregator and resource.

Identify and support existing local food system leaders, projects, events and activities that support Alaska's food system.

\begin{tabular}{|l|l|l|l|l|}
\hline Ideas for Future Research & Possible Partners? & Your Name & Other Notes \\
\hline Topic & Keywords & & & \\
\hline & & & & \\
\hline & & & & \\
\hline & & & & \\
\hline & & & & \\
\hline & & & & \\
\hline
\end{tabular}


Research Workgroup Action Plan

Goal 5 : Alaskans are engaged in our food system.

Objective $5 \mathrm{a}$ : Improve the body of research that will inform and support Alaska food policy efforts.

\section{Action Plan : Current and New Projects and Tasks}

\begin{tabular}{|l|l|l|l|l|}
\hline \multicolumn{2}{|l|}{ Project or Task } & Task Leader + Group & Status + Items Completed & Next Steps \\
\hline 1 & & & & \\
\hline 2 & & & & \\
\hline 3 & & & & \\
\hline 5 & & & & \\
\hline 6 & & & & \\
\hline 7 & & & & \\
\hline
\end{tabular}

Other Projects or Priorities (Workgroup is not involved, but tracking progress of these efforts)

\begin{tabular}{|l|l|l|}
\hline Project or Program & Organization(s) Involved & $\begin{array}{l}\text { AFPC or Workgroup Support } \\
\text { Role? }\end{array}$ \\
\hline & & \\
\hline & & \\
\hline
\end{tabular}

\section{Other Notes}

